\title{
Editorial Note: Content Analysis For Big Multimedia Data
}

Multimedia Tools and Applications gratefully acknowledges the editorial work of the scholars listed below on the special issue entitled, "Content Analysis for Big Multimedia Data."

Of 43 papers submitted to this issue, 16 were eventually accepted after a stringent peerreview process.

Dr. Guoyu Lu (Corresponding Guest Editor)

Advanced Technology Group, ESPN, Bristol, CT, USA

Email: luguoyu62@gmail.com

\section{Dr. Yan Yan}

Department of Information Engineering and Computer Science, University of Trento, Trento, Italy

Email: yan@disi.unitn.it

\section{Prof. Chandra Kambhamettu}

Department of Computer and Information Science

University of Delaware, DE, USA

Email: chandrak@udel.edu 